\title{
Inguinal Bladder Hernia: About 3 Cases
}

\author{
AA Wariss Adegbindin", C Gakosso, A Hajjine, M Benzalim, S Alj
}

Department of Radiology, Ibn Tofail Hospital, CHU Mohamed VI, Marrakech, Cadi Ayyad University, Faculty of Medicine and Pharmacy, Marrakech

DOI: $\underline{10.36347 / \text { sjmcr.2020.v08i11.015 }}$

| Received: 12.10 .2020 | Accepted: 25.10.2020 | Published: 29.11.2020

*Corresponding author: AA Wariss Adegbindin

Abstract

Case Report

Inguinal bladder hernia is a relatively rare, predominantly male condition. The diagnosis is often made by inguinal swelling in a patient over the age of 50 with inguinal swelling associated with disorders of the lower urinary tract in men (LUTS). The diagnosis is confirmed using several medical imaging modalities (UCR, ultrasound, Uro-CT). We report the cases of 3 patients in whom an inguinal hernia of the bladder was suggested on the basis of a clinical suspicion and confirmed by performing a uroscanner. Two patients underwent surgical reduction of the hernia and in one of the patients a prostatic adenomectomy was also done. There were no associated post-operative complications.

Keywords: Bladder; Hernia; Prostatic hypertrophy.

Copyright ( 12020 The Author(s): This is an open-access article distributed under the terms of the Creative Commons Attribution 4.0 International License (CC BY-NC 4.0) which permits unrestricted use, distribution, and reproduction in any medium for non-commercial use provided the original author and source are credited.

\section{INTRODUCTION}

Hernia is the passage of abdominal or pelvic contents through an abdominal wall defect or inguinal canal. It results from the association of a parietal weakness with an increase in intra-abdominal pressure [1]. Although being a frequent entity in digestive surgery, inguinal hernia of the bladder (HIV) is relatively rare. We report 3 cases of inguinal hernia containing the bladder.

\begin{abstract}
Observation 1
62-year-old patient presenting for visceral surgery for an isolated left inguinal swelling, evolving over the past year and associated with dysuria and progressive onset of polyuria. In this history, he had a cholecystectomy 25 years previously. Clinical examination found a left inguinal swelling, the pressure of which made you want to urinate. The biological assessment was normal. The uroscanner performed revealed a thin-walled bladder whose left horn herniated into the left inguinal canal (Figure-1). A hernia repair was performed with no post-opertaive complications.
\end{abstract}
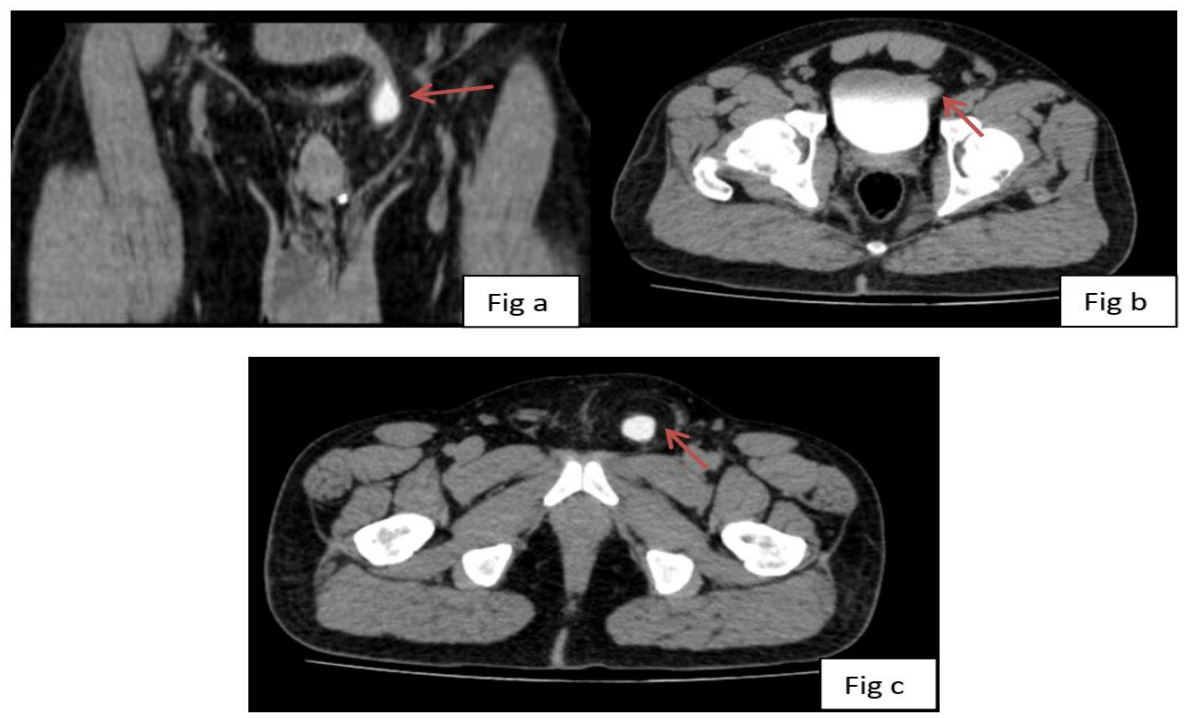

Fig-1: Uroscanner: coronal (a) and axial (b, c) sections at the delayed phase, showing a hernia of the left bladder horn at the inguinal level 


\section{Observation 2}

68-year-old patient with a history of recurrent low back pain that has been evolving for 2 years. He presented to the emergency room for worsening low back pain in a context of apyrexia, without urinary signs or associated voiding disorders. The diuresis was preserved. The clinical examination objectified a right renal sloshing, with a positive Giordano sign as well as the presence of a right inguino scrotal hernia, soft, expansive and reducible. A renal ultrasound was performed and revealed major hydronephrosis of the right kidney. A non-contrast CT scan was performed and showed a right major hydroureteronephrosis upstream of a premeatic stone of 18 x $13 \mathrm{~mm}$, of calcium density, associated with an inguino-scrotal hernia of the right horn of the bladder (Figure-2). The patient was subsequently lost to follow-up.
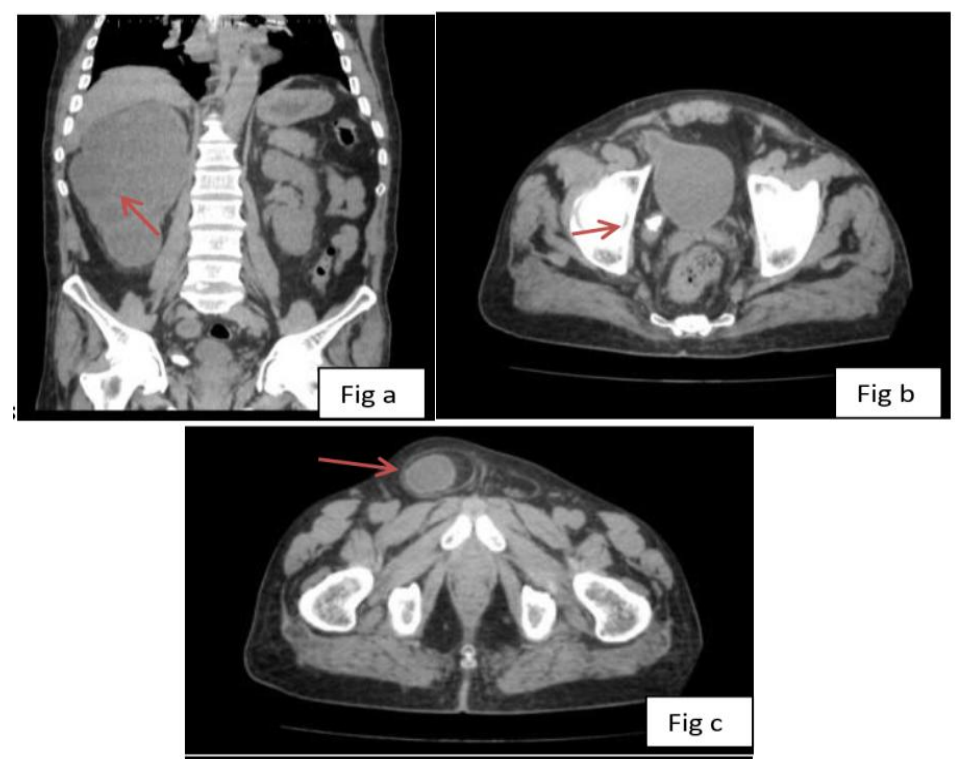

Fig-2: Uroscanner: coronal (a) and axial (b, c) sections at the delayed phase, showing a major right ureterohydronephrosis upstream of a premeatic calculus with inguino-scrotal hernia of the right horn of the bladder

\section{Observation 3}

56-year-old patient with no particular pathological history presented with a soft right inguinal mass evolving for 12 months, associated with a significant ipsilateral scrotal swelling with dysuria. The clinical examination found on palpation an impulsive mass to cough, as well as an enlarged prostate. In the biological assessment, we find a normal PSA level $(<4$ $\mathrm{ng} / \mathrm{mL}$ ). Abdomino-pelvic ultrasound revealed a right hernial sac, the contents of which appear to be fluid and continue with the bladder. The prostate volume was estimated at $57 \mathrm{~cm} 3$. The contrast-enhanced uroscanner found a thin-walled bladder herniating at the right inguino-scrotal level (Figure-3). The patient underwent surgical reduction of the hernia with prostatic adenomectomy and the postoperative follow-up was unremarkable.

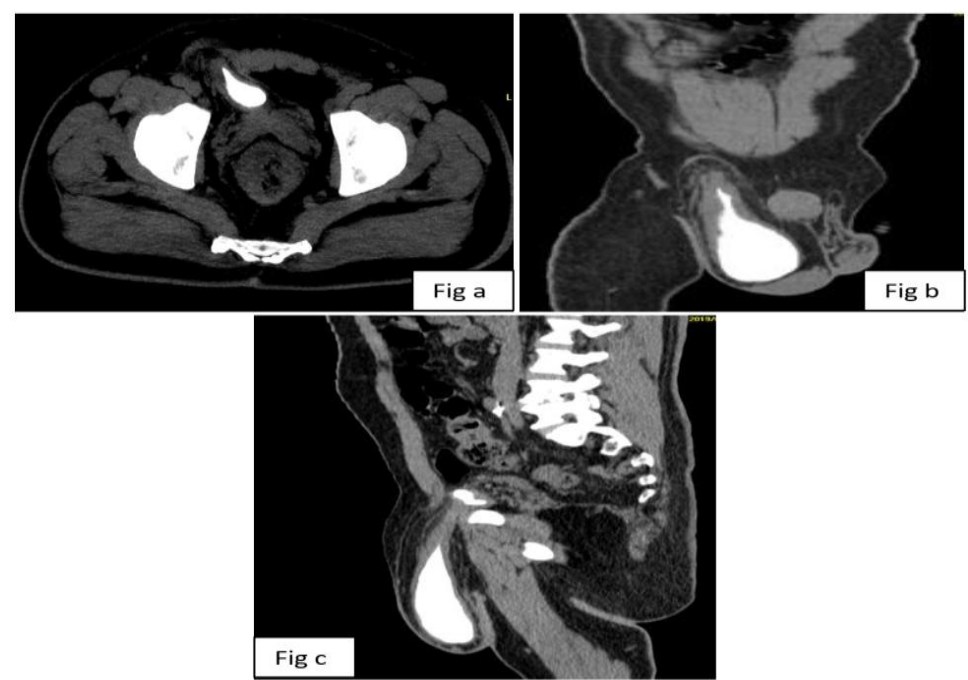

Fig-3: Uroscanner: axial (a) and sagittal (b, c) slices at the delayed phase showing a thin-walled bladder herniating at the right inguino-scrotal level 


\section{DISCUSSION}

The inguinal bladder hernia is a rare entity and constitutes 1 to $5 \%$ of inguinal hernias. Some data report a percentage of $1-3 \%[2,3]$.

The mechanism of formation of this hernia is the subbladder urinary obstruction, responsible for an increase in intrabladder pressure. This explains its predominance among men aged 50 to 70 [4]; since this interval constitutes the period during which the enlarged prostate becomes symptomatic. In the cases reported here, the age of the three patients falls within this interval with an average of 62 years. Thus the prostatic hypertrophy (the volume of which is estimated $57 \mathrm{~cm} 3$ ) found in the 3 rd patient would very probably be the cause of this intra-bladder pressure. In addition, the hypothesis of intra-bladder pressure in response to the premeatic calculus reported in observation 2 , at the origin of the inguinal hernia cannot be excluded.

While men are more predominantly affected, some cases of HIV have been reported in children as well as in women [6].

Inguinal bladder hernia is often asymptomatic. When it is, the main symptom is inguinal and / or scrotal swelling, as is the case in all the patients reported here. It may or may not be accompanied by LUTS mainly related to intra-vesical pressure [3]. This is consistent with the signs presented by the second and third patients (dysuria and polyuria).

In some patients urination is done in two stages. Initially, it is a natural emptying of the bladder, then in a second step urination is possible by manual compression of the hernia $[3,5]$.

Imaging helps to confirm the diagnosis of HIV through different tests. Thus the IVU (intravenous urograpahy) or better the RUC (retrograde urethrocystography) to look for a urethral stenosis, make it possible to make the diagnosis by showing part of the intrahernial bladder [1, 4]. It may reveal a "dog's ear" shaped bladder in the scrotum [3]. These examinations were not performed in our patients. Apart from the RUC, ultrasound allows in some cases to visualize a sac filled with fluid in continuity with the bladder [7]; as reported in observation 3. Should we recall its ease of access and its non-irradiating character. The uro-scanner has the same diagnostic value and will objectifya hernia of the bladder horn emerging through the deep inguinal opening through a more or less narrow neck. All our patients benefited from a uroscanner which made it possible to easily visualize the hernial sac engaged in the inguinal canal. Thus, two right inguino-scrotal hernias and one left inguinal hernia was diagnosed.

CT can also reveal hernias through rare sites like the obturator foramen. HIV is discovered preoperatively in $7 \%$ of cases while in $16 \%$ of cases, it is diagnosed postoperatively $[5,8]$ in front of parietal suppuration or vesico-cutaneous fistula [9]. Besides this complication, HIV can be strangled. The majority of these complications are related to urinary stasis (hydronephrosis, urinary tract infection, acute renal failure) [10, 11]. Rarer complications have been reported such as the occurrence of an intrahernial bladder tumor [12]. Apart from the hydronephrosis reported in the second patient, no other complications were found here.

Finally, when the etiology of the hernia is benign prostatic hypertrophy, medical treatment (alphablockers) should be considered first [13]. If medical treatment has failed, prostate surgery may be considered endoscopically; and hernia treated inguinally [12, 14]. In the event of urinary obstruction requiring surgical treatment, it must be treated first, if not at the same time as the hernia repair, in order to avoid intra-abdominal hyperpressure during urination, the main factor of recurrence hernial [15].

\section{CONCLUSION}

Inguinal bladder hernia is relatively rare but remains a diagnosis to be made in a patient over fifty years of age who presents inguinal swelling associated with LUTS. Adequate imaging is essential to confirm the diagnosis and allow rapid and accurate management.

\section{REFERENCES}

1. Blah M, Nouira Y, Kallel Y, Hafsia GH, Horchani A. Hernie Vésicale. InAnnales de chirurgie 2005 Dec 1 (Vol. 130, No. 10, pp. 633-635). Elsevier Masson.

2. Khan A, Beckley I, Dobbins B, Rogawski KM. Laparoscopic repair of massive inguinal hernia containing the urinary bladder. Urology annals. 2014 Apr;6(2):159-162.

3. Madani AH, Nikouei HM, Aval HB, Enshaei A, Asadollahzade A, Esmaeili S. Scrotal herniation of bladder: a case report. Iranian journal of medical sciences. 2013 Mar;38(1):62-64.

4. Fisher PC, Hollenbeck BK, Montgomery JS, Underwood III W. Inguinal bladder hernia masking bowel ischemia. Urology. 2004 Jan 1;63(1):175-6.

5. Moufid K, Touiti D, Mohamed L. Inguinal Bladder hernia: four case analyzes. Rev Urol. 2013; 15(1): 32-36.

6. Tubbs RS, Loukas M, Shoja MM, Salter EG, Oakes WJ. Indirect inguinal hernia of the urinary bladder through a persistent canal of Nuck: case report. Hernia. 2007 Jun 1;11(3):287-8.

7. Bacigalupo LE, Bertolotto M, Barbiera F, Pavlica P, Lagalla R, Mucelli RS, Derchi LE. Imaging of urinary bladder hernias. American Journal of Roentgenology. 2005 Feb;184(2):546-51. 
8. Kraft KH, Sweeney S, Fink AS, Ritenour CW, Issa MM. Inguinoscrotal bladder hernias: report of a series and review of the literature. Canadian Urological Association Journal. 2008 Dec;2(6):619-623.

9. Alioune S, Cyrille ZO, Yaya S. Inguinal bladder hernia: about 8 cases. The Pan African Medical Journal.

10. Branchu B, Renard Y, Larre S, Leon P. Diagnosis and treatment of inguinal hernia of the bladder: a systematic review of the past 10 years. Turkish journal of urology. 2018 Sep;44(5):384-388.

11. Ptochos A, Iosifidis N. Lithiasic inguinoscrotal herniation of the bladder secondary to prostate enlargement. Acta Radiol. 2002; 43(5):543-544.
12. Caterino M, Finocchi V, Giunta S, De Carli P, Crecco M. Bladder cancer within a direct inguinal hernia: CT demonstration. Abdominal imaging. 2001 Oct 1;26(6):0664-6.

13. Anzaoui JE, Harrech YE, Abbaka N. Inguinal or bladder hernia? Can Urol Assoc J. 2013; 7(1112):e837-9.

14. Bawa AS, Batra RK, Singh R. Management of inguinal hernia with benign prostatic hyperplasia: simultaneous inguinal hernioplasty with transurethral resection of prostate. Int Urol Nephrol. 2003; 35:503-6.

15. Kursh ED, Persky L. Preperitoneal herniorrhaphy. Adjunct to prostatic surgery. Urology 1975; $5: 322-5$. 